\title{
Long-Lasting Effects of Methocinnamox on Opioid Self-Administration in Rhesus Monkeys
}

\author{
David R. Maguire, Lisa R. Gerak, James H. Woods, Stephen M. Husbands, Alex Disney, \\ and Charles P. France

\begin{abstract}
Department of Pharmacology (D.R.M., L.R.G., J.H.W., C.P.F.), Department of Psychiatry (C.P.F.), and Addiction Research, Treatment \& Training Center of Excellence (D.R.M., L.R.G., J.H.W., C.P.F.), University of Texas Health Science Center at San Antonio, San Antonio, Texas; and Department of Pharmacy and Pharmacology, University of Bath, Bath, United Kingdom (S.M.H., A.D.)
\end{abstract}

Received July 26, 2018; accepted November 5, 2018

\begin{abstract}
Opioid abuse remains a serious public health challenge, despite the availability of medications that are effective in some patients (naltrexone, buprenorphine, and methadone). This study explored the potential of a pseudoirreversible mu-opioid receptor antagonist [methocinnamox (MCAM)] as a treatment for opioid abuse by examining its capacity to attenuate the reinforcing effects of mu-opioid receptor agonists in rhesus monkeys. In one experiment, monkeys responded for heroin $(n=5)$ or cocaine $(n=4)$ under a fixed-ratio schedule. Another group $(n=3)$ worked under a choice procedure with one alternative delivering food and the other alternative delivering the mu-opioid receptor agonist remifentanil. A third group $(n=4)$ responded for food and physiologic parameters were measured via telemetry. The effects of MCAM were determined in all experiments and, in some cases, were compared with those of naltrexone.
\end{abstract}

When given immediately before sessions, naltrexone dosedependently decreased responding for heroin and decreased choice of remifentanil while increasing choice of food, with responding returning to baseline levels 1 day after naltrexone injection. MCAM also decreased responding for heroin and decreased choice of remifentanil while increasing choice of food; however, opioid-maintained responding remained decreased for several days after treatment. Doses of MCAM that significantly decreased opioid-maintained responding did not decrease responding for cocaine or food. MCAM did not impact heart rate, blood pressure, body temperature, or activity at doses that decreased opioid self-administration. Because MCAM selectively attenuates opioid self-administration for prolonged periods, this novel drug could be a safe and effective alternative to currently available treatments for opioid abuse.

\section{Introduction}

Opioid abuse remains a serious public health challenge that is responsible for substantial morbidity, mortality, and social costs (Stotts et al., 2009; Birnbaum et al., 2011). In 2016, 11.8 million people in the United States reported misusing an opioid, including heroin and prescription opioid pain relievers, and 2.1 million individuals met the criteria for an opioid use disorder (https://www.samhsa.gov/data/). Despite high rates of abuse, only $15-20 \%$ of individuals receive any type of treatment (Becker et al., 2008; Saloner and Karthikeyan, 2015), and for individuals who receive treatment, there is a high risk for relapse (Lee et al., 2018). Thus, there is an unmet need to expand and improve the treatment of individuals with opioid use disorders.

Medication-assisted therapy is considered the first-line treatment of opioid use disorder, and the currently approved

This work was supported by the National Institutes of Health, National Institute on Drug Abuse [Grants R01DA005018 (C.P.F.) and R01DA007315 (S.M.H.)], and by the Welch Foundation [Grant AQ-0039 (C.P.F.)]. Funding sources had no involvement beyond financial support of this study. The content of this article is solely the responsibility of the authors and does not represent the official views of the National Institutes of Health or the National Institute on Drug Abuse.

https://doi.org/10.1124/jpet.118.252353. medications include methadone, buprenorphine, and naltrexone (Schuckit, 2016). Methadone and buprenorphine have agonist actions at mu-opioid receptors, share many effects with abused opioids such as heroin, and serve as replacements for abused opioids. Although effective in many patients, both drugs have limitations. Methadone is available only through outpatient treatment programs, where it is dispensed daily; the frequency of dosing can be quite burdensome and is not feasible for many patients. Buprenorphine has a relatively long duration of action, and recently developed extendedrelease formulations (e.g., Probuphine; Braeburn Pharmaceuticals, Inc., Plymouth Meeting, PA) increase this duration significantly. However, only specialists can prescribe buprenorphine, and implants require minor surgical procedures for insertion and removal, limiting the number of health-care providers that are available and/or willing to prescribe this drug. Because of agonist effects, treatment with methadone and buprenorphine can result in physical dependence and carries a risk for diversion and overdose. Moreover, agonists at mu-opioid receptors interact with other drugs such as alcohol and benzodiazepines to produce potentially dangerous drugdrug interactions (Hall et al., 2008; Jones et al., 2012, 2014; Jones and McAninch, 2015). 
Naltrexone (Revia; Duramed Pharmaceuticals, Inc., Pomona, $\mathrm{NY}$ ) is an opioid receptor antagonist that blocks the effects of opioids. Although naltrexone avoids abuse liability and adverse effects associated with methadone and buprenorphine, its pharmacological properties limit its effectiveness. Naltrexone has a relatively short duration of action and binds to opioid receptors in a competitive, reversible manner; therefore, its antagonist effects can be surmounted by administering large doses of an agonist. An injectable extended-release formulation of naltrexone (Vivitrol; Alkermes, Inc., Dublin, Republic of Ireland) increases its duration of action significantly but does not mitigate the fact that its antagonist actions are surmountable. Moreover, the administration of an opioid antagonist can precipitate withdrawal in opioid-dependent individuals; thus, naltrexone is used in patients after a period of detoxification from opioids. In summary, although currently available medications are effective for opioid abuse in some patients, there is a significant need for more and better approaches to treat this public health emergency (Volkow and Collins, 2017).

Methocinnamox (MCAM) is an opioid receptor antagonist, developed as a pharmacological tool that selectively eliminates mu-opioid receptors. MCAM attenuates the binding of the selective mu-opioid receptor ligand $\left[{ }^{3} \mathrm{H}\right] \mathrm{DAMGO}$ in washed membranes obtained from mice, suggesting that MCAM binds in a functionally pseudoirreversible manner (Broadbear et al., 2000). Irreversible drugs such as $\beta$-funaltrexamine bind covalently to receptors (Portoghese et al., 1980); however, drugs such as clocinnamox, buprenorphine, and MCAM are thought to be pseudoirreversible insofar as they dissociate very slowly from receptors but do not form a covalent bond. MCAM was shown to be an effective antagonist of mu-opioid receptormediated effects in vivo. For example, MCAM attenuated the antinociceptive effects of morphine in mice and rats (Broadbear et al., 2000; Peckham et al., 2005) and was superior to irreversible (e.g., $\beta$-funaltrexamine) and other pseudoirreversible (e.g., clocinnamox) mu-opioid receptor antagonists with respect to potency and selectivity at mu-opioid receptors (Broadbear et al., 2000). Previous studies (Negus et al., 1993; Martin et al., 1995, 1998; Zernig et al., 1997) have demonstrated the effectiveness of irreversible and pseudoirreversible mu-opioid receptor antagonists for blocking opioid self-administration in nonhuman subjects. However, the impact of MCAM on abuse-related effects of opioids, including self-administration, has not been characterized.

This study explores the therapeutic potential of MCAM for treating opioid abuse by examining its capacity to attenuate opioid self-administration in rhesus monkeys. In one experiment, intravenous infusions of heroin or cocaine were delivered according to a fixed-ratio schedule of reinforcement. The effects of MCAM were compared with those of naltrexone, which is the only antagonist approved for treating opioid abuse. Effects on cocaine self-administration were determined to characterize the selectivity of MCAM for attenuating opioid-maintained behavior. In a second experiment, monkeys could choose between food and intravenous infusions of the mu-opioid receptor agonist remifentanil. This experiment extends the evaluation of MCAM to include another opioid receptor agonist, the ultrapotent and short-acting fentanyl analog remifentanil. Under choice procedures, changes in reinforcing effects are characterized based on the allocation of behavior among alternatives, rather than overall response output that can be sensitive to many factors other than reinforcing effectiveness. In a third experiment, responding for food and physiologic parameters (heart rate, blood pressure, temperature, and activity) were monitored to characterize the direct effects of MCAM, including its effects on responding maintained by a nondrug reinforcer.

\section{Materials and Methods}

Animals. Thirteen adult rhesus monkeys (10 males [AC, AP, DU, FI, GI, LO, MA, MO, TI, and WI] and three females [NI, PR, and RU]), weighing between 6.2 and $14.6 \mathrm{~kg}$, were housed individually in stainless steel cages in colony rooms maintained under a 14-/10-hour light/dark cycle (lights on at 6:00 AM). Monkeys were fed chow (High Protein Monkey Diet; Harlan Teklad, Madison, WI), fresh fruit, peanuts, and other treats daily to maintain body weight, and water was available continuously. Studies were carried out in accordance with the Guide for the Care and Use of Laboratory Animals, as adopted and promulgated by the US National Institutes of Health (National Research Council, 2011), and were approved by the University of Texas Health Science Center at San Antonio Institutional Animal Care and Use Committee.

Surgery. Monkeys were sedated with $10 \mathrm{mg} / \mathrm{kg}$ (i.m.) ketamine (Henry Schein Animal Health, Dublin, OH), intubated, and then maintained on $2 \mathrm{l} / \mathrm{min}$ oxygen and isoflurane anesthesia (Butler Animal Health Supply, Grand Prairie, TX). Penicillin B\&G (40,000 $\mathrm{IU} / \mathrm{kg})$ and meloxicam $(0.1-0.2 \mathrm{mg} / \mathrm{kg})$ were given postoperatively. During surgery and under anesthesia, an intravenous catheter or a telemetry transmitter was implanted. For monkeys in the heroin and/or cocaine self-administration study, a 5-French polyurethane catheter (Access Technologies, Skokie, IL) was inserted into a jugular, femoral, or subclavian vein, tunneled subcutaneously to the midscapular region of the back, and attached to a subcutaneous vascular access port (MIDA-PU-C50; Access Technologies). For monkeys in the choice study, a 5-French polyurethane catheter was inserted into a vein, tunneled to the mid-scapular region of the back, passed through a flexible stainless steel tether (Lomir Biomedical, Notre-Dame-del'Île-Perrot, QC, Canada), and connected to an 18-gauge singlechannel fluid swivel (Lomir Biomedical) that was secured to the rear wall of the home cage. The opposite side of the swivel, located outside of the cage, was attached to a $30-\mathrm{ml}$ syringe mounted in a syringe pump (Razel Scientific Instruments, Fairfax, VT). Monkeys wore a jacket (Lomir Biomedical) that protected the catheter and secured the tether. For monkeys in the study in which responding was maintained by food, a telemetry transmitter (PhysioTel Digital Implant Model L11; Data Science International, St. Paul, MN) was placed in the left or right flank, with positive ECG leads tunneled to the lower-left quadrant of the thorax, negative ECG leads tunneled to the top right quadrant, and the systemic blood pressure catheter tunneled to and inserted into the left or right femoral artery. During the course of the study, monkeys in the choice and food-maintained responding studies were sedated every 2 weeks with $10 \mathrm{mg} / \mathrm{kg}$ ketamine to obtain an updated body weight, confirm catheter patency (choice study only), perform routine health checks, and inspect the equipment.

Heroin and Cocaine Self-Administration. Five monkeys (AC, LO, NI, PR, and RU) participated in the heroin self-administration experiment and four monkeys (AC, FI, LO, and PR) participated in the cocaine self-administration experiment; all had experience lever-pressing for intravenous infusions of drug, including heroin and/or cocaine. Three monkeys (AC, LO, and PR) participated in both experiments.

Sessions were conducted 7 days/week. Monkeys were seated in primate chairs (Model R001; Primate Products, Miami, FL) and positioned in sound-attenuating operant-conditioning chambers containing two horizontally aligned response levers located approximately $32 \mathrm{~cm}$ apart. Above each lever was a circular, translucent disk that could be transilluminated green or red. Self-administered drug infusions were delivered intravenously by connecting a $185-\mathrm{cm}$ 
extension set (Abbott Laboratories, Stone Mountain, GA) to the vascular access port by a 20-gauge Huber-point needle (Access Technologies). The distal end of the extension set was connected to a 30 - or 60-ml syringe mounted in a syringe pump (PHM-100; Med Associates, Fairfax, VT) located outside the chamber. White noise and an exhaust fan masked extraneous sounds. Experimental events were arranged, and data were recorded through an interface (Med Associates) connected to a PC computer operating Med-PC IV software (Med Associates).

Prior to the start of the session, the port and catheter were flushed with $5 \mathrm{ml}$ of a sterile $0.9 \%$ saline solution, and a syringe and extension set containing the solution available for self-administration that day was connected to the Huber-point needle and mounted in the syringe pump. One minute before the start of the session, the pump was activated to load the catheter with the new solution. Sessions began with noncontingent delivery of a priming infusion; a red light over the active lever was illuminated for 5 seconds, and the dose of drug available for self-administration during that session was delivered. Immediately after the priming infusion, the light above the active lever (side counterbalanced across monkeys) was illuminated, with a green light signaling the beginning of the response period. Thirty consecutive responses (fixed-ratio 30 schedule) on the active lever changed the light from green to red for 5 seconds and delivered an intravenous infusion. Completion of the response requirement also initiated a 180-second timeout, during which all lights were off (except for the red light, which was illuminated for 5 seconds), and responses were recorded but had no programmed consequence. After the timeout, the light was again illuminated green, signaling the next response period. Responses on the other (inactive) lever during response periods reset the response counter for the active lever and had no other programmed consequence. Lever designations remained constant for each monkey for the duration of the study. Sessions lasted for 90 minutes, inclusive of response and timeout periods. At the end of the session, the catheter and port were flushed and locked with $3 \mathrm{ml}$ of heparinized saline $(100 \mathrm{U} / \mathrm{ml})$ to maintain catheter patency.

In some sessions, monkeys could respond for heroin $(0.0032 \mathrm{mg} / \mathrm{kg}$ per infusion), and in other sessions they could respond for cocaine (0.032 $\mathrm{mg} / \mathrm{kg}$ per infusion). Occasionally, monkeys received a subcutaneous injection prior to the session (described below). The following four types of tests were conducted: 1) naltrexone pretreatment with heroin self-administration; 2) MCAM pretreatment with heroin self-administration; 3) naltrexone pretreatment with cocaine self-administration; and 4) MCAM pretreatment with cocaine selfadministration. Pretreatment injections were given 15 or 60 minutes prior to the session for tests with naltrexone and MCAM, respectively. Each test comprised multiple sessions, with saline injections given subcutaneously 15 or 60 minutes before the session, depending on the test, for at least one session prior to and after each test injection; during tests with MCAM, saline injections were given 60 minutes prior to the session for three sessions after the test injection.

Effects of naltrexone and MCAM on heroin self-administration were determined in five monkeys (AC, LO, NI, PR, and RU). A naltrexone dose-effect curve was determined three times during the experiment. Each determination began once responding for heroin was stable, as defined by three consecutive sessions in which the average number of infusions obtained in each of those sessions varied by not more than $\pm 20 \%$ of the three-session mean. Doses of naltrexone $(0.0032$, 0.01 , and $0.032 \mathrm{mg} / \mathrm{kg}$ ) were tested in an irregular order; on one occasion, $0.1 \mathrm{mg} / \mathrm{kg}$ naltrexone was tested in one monkey to complete the dose-response curve in that subject. After the first dose of naltrexone was tested, additional doses were tested when the number of infusions obtained during a single session was $\geq 80 \%$ of the initial 3 -day baseline. For the first naltrexone dose-effect curve determination, each dose was tested twice, and the effects of each dose were averaged. For subsequent naltrexone determinations (see below), each dose was tested only once. The effects of MCAM $(0.032$ and $0.32 \mathrm{mg} / \mathrm{kg})$ on heroin self-administration were determined in the same five monkeys once responding for heroin was stable according to the 3-day criterion described above; tests with MCAM were separated by at least 3 weeks and a redetermination of the naltrexone dose-effect curve to confirm that the potency of naltrexone was not different from the initial determination. Because the duration of the effect of MCAM differed across monkeys, repeated testing with naltrexone within individual subjects provided evidence for each individual that the sensitivity of opioid receptors had been restored between consecutive tests with MCAM. The effects of naltrexone and MCAM on cocaine self-administration were determined in four monkeys (AC, FI, LO, and $\mathrm{PR}$ ) once responding for cocaine was stable according to the 3-day criterion described above. Naltrexone $(0.032 \mathrm{mg} / \mathrm{kg})$ was tested first followed at least 3 days later by MCAM $(0.32 \mathrm{mg} / \mathrm{kg})$. Heroin and cocaine were dissolved in $0.9 \%$ sterile saline and delivered intravenously in a volume of $1 \mathrm{ml} / 10 \mathrm{~kg}$ b.wt. Naltrexone and MCAM were dissolved in sterile water and delivered subcutaneously in the lower part of the back in a volume of $1.0-2.1 \mathrm{ml} / 10 \mathrm{~kg}$ b.wt. Multiple injections were given when the total volume exceeded $0.8 \mathrm{ml}$.

Remifentanil Versus Food Choice. Three monkeys (GI, MO, and WI) participated in the choice experiment; all had experience lever pressing for food and intravenous infusions (Maguire and France, 2018). For these monkeys, the home cage $(81 \mathrm{~cm}$ tall by $81 \mathrm{~cm}$ wide by $72 \mathrm{~cm}$ deep) also served as the experimental chamber. A stainless steel instrument panel ( $20 \mathrm{~cm}$ high by $28 \mathrm{~cm}$ wide) was mounted on one wall of the cage. The panel contained two levers ( $4.5 \mathrm{~cm}$ wide) horizontally aligned $23 \mathrm{~cm}$ above the floor and spaced $15 \mathrm{~cm}$ apart center to center. Three stimulus lights were horizontally aligned $5 \mathrm{~cm}$ above the levers. A $6 \mathrm{~cm}$ high by $5 \mathrm{~cm}$ wide aperture was located directly above the instrument panel through which 300-mg raspberry flavored sucrose pellets (5TUT; Test Diet, Richmond, IN) were delivered via activation of a pellet dispenser (Med Associates).

Sessions were conducted 7 days/week and comprised four blocks. Each block began with 2 sample trials, followed by 10 choice trials. At the beginning of a sample trial, the light above one lever was illuminated green, and 30 consecutive responses on the lever directly below that light turned the side light off, turned on the white center light for 2 seconds, initiated a 180-second timeout, and delivered the reinforcer (one 300-mg sucrose pellet or an intravenous infusion) associated with that lever for the current block. Responses during the timeout had no programmed consequence. After the timeout, the other side light was illuminated green, and 30 responses on the lever directly below that light delivered the associated reinforcer followed by a timeout. The order of sample trials varied randomly across blocks, and both sample trials had to be completed before choice trials were presented. During choice trials, both side lights were illuminated green, and 30 consecutive responses on either lever delivered the reinforcer associated with that lever. For all trials, responses on one lever reset the response requirement for the other lever. The block ended after 45 minutes or the completion of 12 trials ( 2 sample trials plus 10 choice trials), whichever occurred first. Blocks were separated by a 5 -minute blackout. If all trials were completed before the block ended, then the blackout was extended to include the remaining time in the block plus the blackout time. The catheter was flushed and locked with $3 \mathrm{ml}$ of heparinized saline $(100 \mathrm{U} / \mathrm{ml})$ at the end of each session to maintain catheter patency.

During some sessions, the dose of remifentanil available increased in half-log units across blocks from 0.032 to $1.0 \mu \mathrm{g} / \mathrm{kg}$ per infusion. Occasionally, saline was substituted for remifentanil in all the blocks (saline-only session) to ensure that responding was sensitive to the availability of remifentanil rather than time in the session. Food was always available for responding on one lever, and an infusion was always available for responding on the other lever; lever designations (e.g., food, left; infusion, right) remained constant for individual monkeys for the duration of the experiment.

Tests were conducted once remifentanil dose-effect curves were stable, as indicated by three consecutive sessions in which more than 36 choice trials $(90 \%)$ were completed and the percentage choice of drug across all blocks of the session did not vary by more than $20 \%$. 
Because many choice patterns can produce identical percentages of drug choice for the entire session, visual inspection of the data also confirmed that the remifentanil dose-effect curves increased in a monotonic fashion. The following three types of tests were conducted: 1) naltrexone pretreatment given immediately before a remifentanil choice session; 2) naltrexone pretreatment given 24 hours prior to a remifentanil choice session; and 3) MCAM pretreatment given 24 hours prior to a remifentanil choice session. To ensure that 24 hours intervened between the injection of an antagonist and the availability of remifentanil during a choice session, MCAM and naltrexone (24-hour pretreatment) were given immediately prior to a salineonly choice session. Remifentanil was available during the next session and for each session thereafter. Tests with MCAM were separated by at least 3 weeks. All pretreatments were delivered intravenously through the catheter line (followed by a saline flush) immediately prior to the start of a session. Remifentanil, naltrexone, and the smallest dose of MCAM tested in this experiment $(0.32 \mathrm{mg} / \mathrm{kg})$ were dissolved in $0.9 \%$ sterile saline and delivered in a volume of $1 \mathrm{ml} / 10 \mathrm{~kg}$ b.wt. The two larger doses of MCAM (1.0 and $3.2 \mathrm{mg} / \mathrm{kg}$ ) were dissolved in a solution of saline containing $10 \% \mathrm{w} / \mathrm{v} \beta$-cyclodextrin and injected in volumes of 1.0-3.2 ml/10 kg b.wt. Comparable volumes of saline or $\beta$-cyclodextrin vehicle alone were administered prior to control sessions.

Food-Maintained Responding and Physiologic Effects. Four monkeys (AP, DU, MA, and TI) participated in this experiment; all had experience lever pressing for food. For these monkeys, behavioral sessions and acquisition of telemetry data were conducted in their home cages, which were identical to those described for the choice experiment, although these monkeys did not wear a jacket or tether.

Behavioral sessions were conducted daily, 7 days/week, and comprised five 10-minute blocks that began at 30-minute intervals. The beginning of a block was signaled by illumination of the green light above the right lever. When the light was on, 10 responses on the right lever delivered one 300-mg raspberry flavored sucrose pellet and turned off the green light for 0.5 second. Responses on the left lever reset the response requirement on the right lever; blocks lasted for up to 10 food presentations or 10 minutes, whichever occurred first. All stimulus lights were turned off between blocks and responding during that time had no programmed consequence. Telemetry data were acquired using the Ponemah Software System (version 5.2) and associated hardware (Data Science International); measures included arterial blood pressure (in millimeters of mercury), heart rate (in beats per minute), body temperature (in degrees Celsius), and activity (in number of counts).

Tests were conducted once food-maintained responding was stable, as indicated by three consecutive sessions in which the average response rate for each of those three sessions (aggregated across all five blocks of the session) did not deviate from the overall mean of those three sessions by more than $20 \%$. A vehicle injection was administered 1 hour prior to the session on the first day of the test, and MCAM was administered 1 hour prior to the session on the following day. Sessions were conducted thereafter, but no further injections were administered. Telemetry data were collected every minute for 48 hours, beginning with the vehicle injection on the first day of the test. The smaller dose of MCAM $(0.32 \mathrm{mg} / \mathrm{kg})$ was tested first in four monkeys. Because of a limited supply of drug, the larger dose of MCAM ( $3.2 \mathrm{mg} / \mathrm{kg}$ ) was tested later in only two monkeys (DU and MA); injections of MCAM were separated by 33 days. For the first test $(0.32 \mathrm{mg} / \mathrm{kg})$, sessions began at 1000 hours, and for the second test $(3.2 \mathrm{mg} / \mathrm{kg})$, sessions began at 1200 hours. Monkeys were given their daily food ration approximately 2 hours after the session ended. MCAM was dissolved in $10 \% \mathrm{w} / \mathrm{v} \beta$-cyclodextrin vehicle and injected subcutaneously into the lower back in volumes of $1.0-3.2 \mathrm{ml} / 10 \mathrm{~kg}$ b.wt. Multiple injections were given when the total volume exceeded $0.8 \mathrm{ml}$; a comparable number of injections of vehicle alone were administered on day 1 of each test.

Drugs. Heroin (3,6-diacetylmorphine) hydrochloride, naltrexone hydrochloride, remifentanil hydrochloride, and cocaine hydrochloride were generously provided by the National Institute on Drug Abuse Drug Supply Program (Rockville, MD). MCAM was synthesized as previously described (Broadbear et al., 2000). Doses were calculated using the salt form. 2-Hydroxypropyl- $\beta$-cyclodextrin was purchased (Accela ChemBio, Inc., San Diego, CA) and dissolved in $0.9 \%$ sterile saline at a concentration of $0.1 \mathrm{~g} / \mathrm{ml}$.

Data and Statistical Analyses. For the heroin and cocaine selfadministration experiments, the primary dependent measure was the number of infusions obtained during each session. The effects of naltrexone and MCAM on heroin self-administration were analyzed using a two-way, repeated-measures analysis of variance (ANOVA) with session and dose as within-subject factors. Tests with naltrexone comprised three consecutive sessions, beginning with the session immediately preceding naltrexone administration and ending with the the session that occurred the day after naltrexone. Tests with MCAM comprised at least 10 sessions, beginning with the session immediately preceding MCAM and ending at least eight sessions after MCAM administration. Because of variation in the duration of the effect of MCAM across individual subjects, only data from the first 8 days after MCAM administration were included in the analysis. Effects of naltrexone and MCAM on cocaine self-administration were analyzed using a one-way, repeated-measures ANOVA with session as the factor. Post hoc analyses were conducted using Dunnett's test with data collected after the administration of an antagonist compared to the baseline session. The potency of naltrexone for decreasing heroin self-administration was quantified by plotting the number of infusions obtained as a function of the logtransformed (base 10) dose of naltrexone. Dose-effect data for individual subjects were then fit with a straight line using linear regression, and the slope and the $y$-intercept were used to estimate the dose of naltrexone that decreased the number of infusions obtained by $50 \%\left(\mathrm{ED}_{50}\right)$. The $\mathrm{ED}_{50}$ of naltrexone was analyzed across three determinations using a one-way, repeated-measures ANOVA with determination as a factor.

For the food/drug choice experiment, the primary dependent measures were the percentage of drug choice and the total number of choice trials completed. The percentage of drug choice was calculated for each block by dividing the number of choices of drug (i.e., ratios completed on the drug lever during choice trials) by the total number of choices (e.g., ratios completed on either lever during choice trials) and multiplying by 100; the percentage of drug choice for the entire session was calculated the same way except that the number of choices of drug and the total number of choices were aggregated across blocks. The percentage of drug choice and trials completed were plotted as a function of remifentanil dose. Whenever possible, remifentanil dose-effect curves for individual subjects were fit with a straight line using linear regression and only data on the linear portion of the dose-effect curve. The slope and the $y$-intercept were used to estimate the dose of remifentanil that produced $50 \%$ drug choice (i.e., the $\mathrm{ED}_{50}$ ). Shifts in the remifentanil dose-effect curve after pretreatment with an antagonist were quantified by calculating a potency ratio, which was the $\mathrm{ED}_{50}$ after a test divided by the control $\mathrm{ED}_{50}$. Control dose-effect curves were generated using data from the most recent remifentanil choice session conducted before a test. The effects of MCAM on the percentage of drug choice and trials completed for each session were analyzed using a two-way, repeated-measures ANOVA, with session and dose of MCAM as within-subject factors.

For the experiment on food-maintained responding and telemetry, the rate of responding for each block was calculated by dividing the total number of responses on the right lever while the green light was illuminated by the total amount of time that the green light was illuminated. There were no systematic differences across blocks; therefore, the rate for the entire session was aggregated by taking the average across blocks. Because the number of subjects differed between tests (four for $0.32 \mathrm{mg} / \mathrm{kg}$ and two for $3.2 \mathrm{mg} / \mathrm{kg}$ ), the effects of each dose of MCAM on food-maintained responding were analyzed separately using a one-way, repeated-measures ANOVA with session 

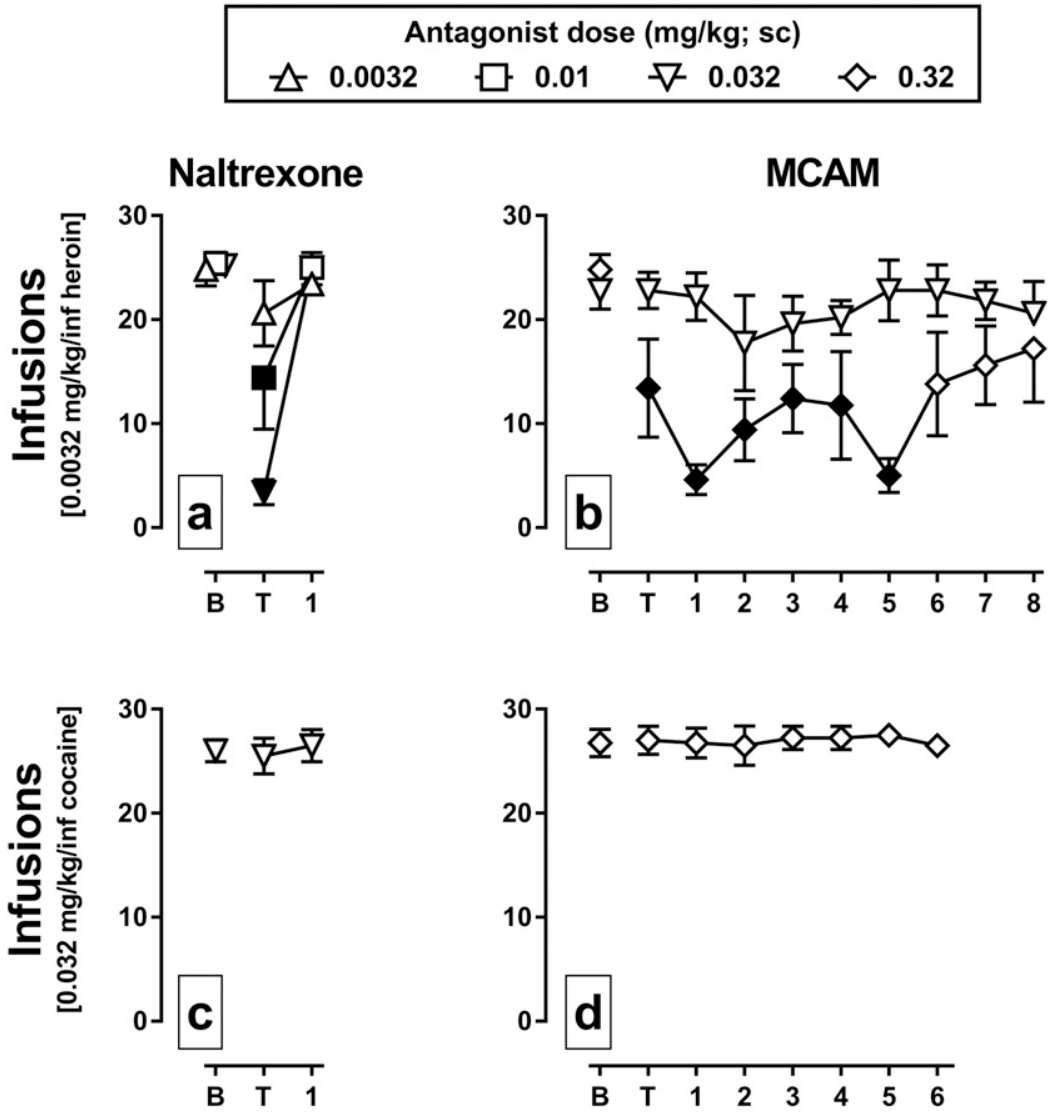

Session

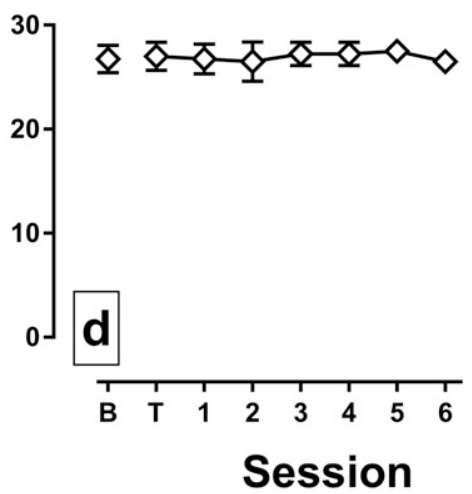

Fig. 1. Effects of naltrexone and MCAM on the selfadministration of heroin or cocaine in rhesus monkeys. The mean ( \pm 1 S.E.M.) number of infusions of $0.0032 \mathrm{mg} / \mathrm{kg}$ per infusion heroin (a and $\mathrm{b} ; n=5$ ) or $0.032 \mathrm{mg} / \mathrm{kg}$ per infusion cocaine ( $c$ and $d ; n=4$ ) is plotted across consecutive sessions. Data points above B indicate the number infusions obtained during the session preceding the administration of an antagonist. Data points above $\mathrm{T}$ indicate the number of infusions obtained during the session immediately after the administration of an antagonist; the pretreatment time for naltrexone ( $\mathrm{a}$ and $\mathrm{c}$ ) was 15 minutes, and the pretreatment time for MCAM (b and d) was 60 minutes. The abscissae show the time in days since the injection of an antagonist. Filled symbols indicate data that are significantly different from baseline according to a Dunnett's post hoc test $(P<$ $0.05)$. as the factor. Data used for the analysis were taken from six consecutive sessions, beginning with the session immediately preceding MCAM administration (i.e., after vehicle administration) and including the 4 days after MCAM administration. Data obtained via telemetry were collected every minute and then averaged for each hour for 48 hours, beginning with the vehicle injection on the first day of the test. Telemetry data were analyzed separately for each dose of MCAM using a two-way, repeated-measures ANOVA with treatment (vehicle or MCAM) and hour as within-subject factors. All of the data collected after the vehicle injection were compared on an hourly basis to the corresponding time-point after MCAM injection the following day. For significant treatment-by-hour interactions, a Dunnett's post hoc test was used to compare data for each hour obtained after vehicle administration on the first day to data obtained during the corresponding hour the next day after MCAM administration.

Dose-effect curves were fit using Excel 2016 (Microsoft, Redmond, WA), and data analyses were conducted using NCSS version 10.0.13 (NCSS Statistical Software, Kaysville, UT).

\section{Results}

Heroin and Cocaine Self-Administration. When $0.0032 \mathrm{mg} / \mathrm{kg}$ per infusion of heroin was available for self-administration, the group average number of infusions obtained during sessions that immediately preceded administration of an antagonist ranged from 22.8 to 25.4 (Fig. 1, a and $\mathrm{b}$, data above B). Naltrexone dose-dependently decreased infusions obtained on the day of treatment (Fig. 1a, data above T) with responding returning to baseline levels the next day (Fig. 1a, data above 1); these data represent the effects of naltrexone from the first determination of the dose-effect curve. For naltrexone, there was a significant main effect of session $[F(2,44)=37.45, P<0.001]$, a significant main effect of dose $[F(2,44)=5.37, P=0.01]$, and a significant sessionby-dose interaction $[F(4,44)=7.28, P<0.001]$. Infusions obtained on the day of treatment with 0.01 and $0.032 \mathrm{mg} / \mathrm{kg}$ naltrexone were significantly different from baseline (filled symbols). The mean $\mathrm{ED}_{50}$ value for the first naltrexone determination was $0.011 \mathrm{mg} / \mathrm{kg}$ [95\% confidence interval (CI), 0.007-0.016], which was not significantly different from the second $[0.009 \mathrm{mg} / \mathrm{kg}(95 \% \mathrm{CI}, 0.002-0033)]$ or third $[0.011 \mathrm{mg} / \mathrm{kg}$ (95\% CI, 0.005-0.018)] determinations according to one-way ANOVA ( $P=0.93$; data not shown). MCAM also dose-dependently decreased the infusions of heroin obtained (Fig. 1b). There was a significant main effect of session $[F(9,97)=2.99, P=0.004)$, a significant main effect of dose $[F(1,97)=55.3, P<0.001]$, and a significant session-by-dose interaction $[F(9,97)=2.63, P=$ $0.01]$. Infusions obtained on the day of treatment with $0.32 \mathrm{mg} / \mathrm{kg} \mathrm{MCAM}$ and 5 days thereafter were significantly different from baseline. When $0.032 \mathrm{mg} / \mathrm{kg}$ per infusion cocaine was available for self-administration, the group average number of infusions obtained during sessions that immediately preceded the administration of an antagonist ranged from 26.0 to 26.8 (Fig. 1, c and d, data above B). Neither naltrexone $(0.032 \mathrm{mg} / \mathrm{kg}$ ) (Fig. 1c) nor MCAM $(0.32 \mathrm{mg} / \mathrm{kg})($ Fig. 1d) significantly altered the number of cocaine infusions obtained $(P=0.49$ and $P=0.88$, respectively). 

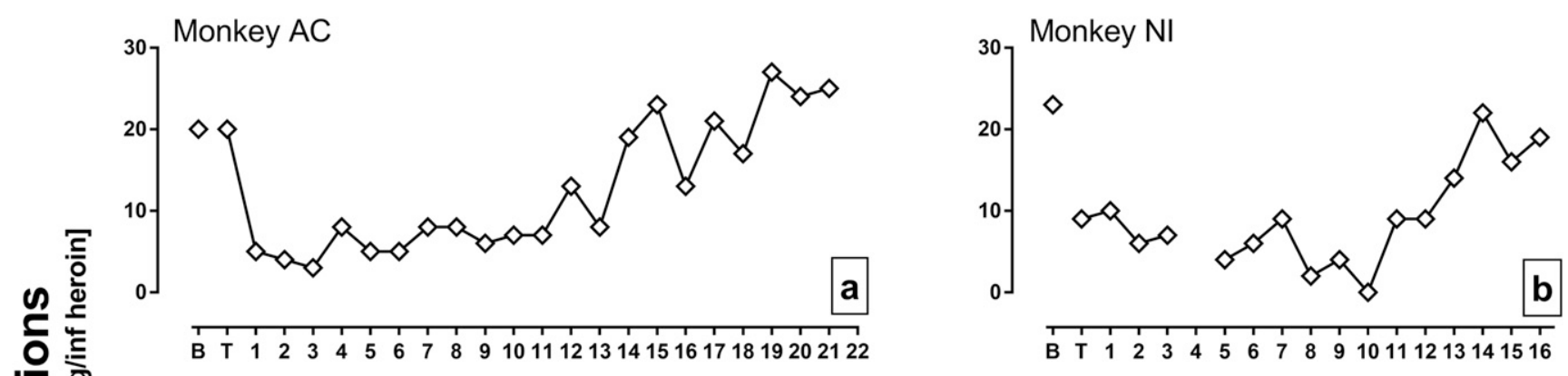

Monkey RU

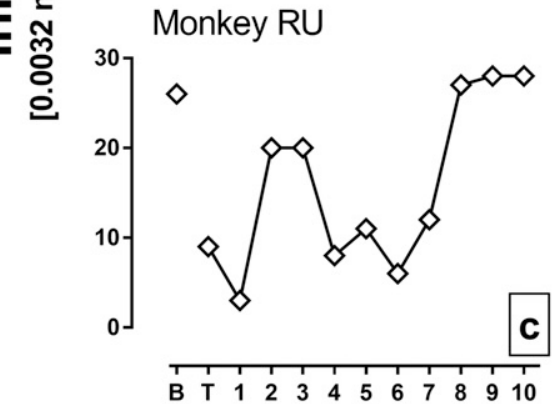

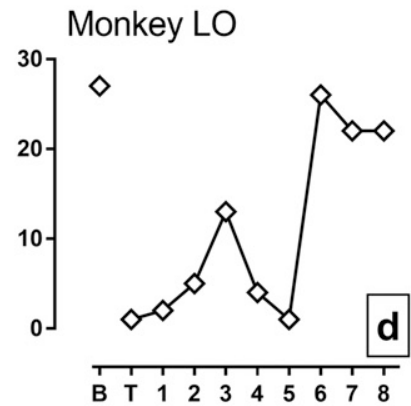

Session

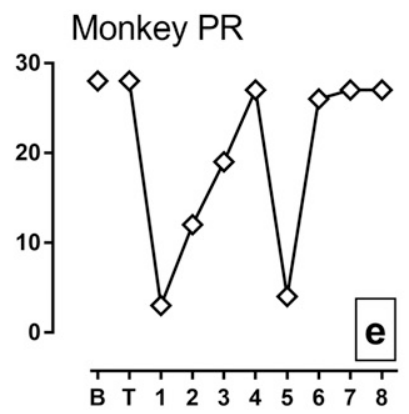

Fig. 2. Effects of $0.32 \mathrm{mg} / \mathrm{kg}$ MCAM on self-administration of $0.0032 \mathrm{mg} / \mathrm{kg}$ per infusion heroin for individual monkeys (panels a-e). Data are the same as plotted in Fig. 1, and other details are the same as in Fig. 1.

Figure 2 shows the effects of $0.32 \mathrm{mg} / \mathrm{kg}$ MCAM on heroin self-administration in individual monkeys. Responding for heroin was decreased for an average $( \pm 1$ S.D. $)$ of $9.6 \pm 5.7$ sessions before returning to stable levels near baseline (according to the three-session criterion), though there was some variability across monkeys. For monkeys AC and NI, the number of heroin infusions obtained was reduced for 18 and 13 sessions, respectively, after MCAM injection (Fig. 2, a and b). For monkeys RU and LO, the number of heroin infusions obtained was below baseline levels for seven and five sessions, respectively, after MCAM injection (Fig. 2, c and d). For monkey PR, responding reached stability 8 days after treatment, but effects were less consistent across sessions; nevertheless, the number of infusions obtained was below baseline for four of the first six sessions after MCAM injection (Fig. 2e).

Remifentanil Versus Food Choice. In monkeys responding under the food/drug choice procedure, choice of remifentanil increased (Fig. 3a, circles) and choice of food decreased (Fig. 3c, circles) across blocks as the dose of remifentanil increased, with doses of 0.32 and $1.0 \mu \mathrm{g} / \mathrm{kg}$ per infusion maintaining at least $80 \%$ drug choice (Fig. $3 \mathrm{~b}$ ). The mean $\mathrm{ED}_{50}$ value of the control remifentanil dose-effect curve for percentage of drug choice was $0.18 \mu \mathrm{g} / \mathrm{kg}$ per infusion. The injection of $0.032 \mathrm{mg} / \mathrm{kg}$ naltrexone immediately before a remifentanil versus food choice session decreased choice of remifentanil and increased choice of food, shifting the remifentanil dose-effect curve rightward, on average, 3.1-fold (95\% CI, 3.0- to 3.2-fold) (inverted triangles), and not altering the number of trials completed (Fig. 3d). The remifentanil dose-effect curve returned to control the next day (upright triangles). On a separate occasion, the same dose of naltrexone was administered 24 hours before a remifentanil choice session (i.e., without an intervening remifentanil session), and it did not alter the remifentanil dose-effect curve for the percentage of drug choice, although the number of choice trials completed decreased in some blocks (squares).

MCAM significantly attenuated the percentage choice of remifentanil, shifting the remifentanil dose-effect curve rightward and downward in a dose-dependent manner (Fig. 4, top row), and in most cases without altering the number of trials completed (Fig. 4, bottom row). For example, $0.32 \mathrm{mg} / \mathrm{kg}$ MCAM decreased choice of $0.32 \mu \mathrm{g} / \mathrm{kg}$ per infusion of remifentanil from $100 \%$ to $0 \%$ and choice of the larger dose of remifentanil from $100 \%$ to $50 \% 1$ day after the injection of MCAM (Fig. 4a, upright triangles). The two larger doses of MCAM (1.0 and $3.2 \mathrm{mg} / \mathrm{kg})$ reduced choice of all doses of remifentanil to $0 \% 1$ day after treatment (Fig. $4, \mathrm{~b}$ and c). The time to recovery of the remifentanil dose-effect curve was also related to the dose of MCAM, with the curve fully recovering by 4 days after administration of $0.32 \mathrm{mg} / \mathrm{kg}$ MCAM (squares), by 8 days after $1.0 \mathrm{mg} / \mathrm{kg}$ (diamonds), and by 12 days after $3.2 \mathrm{mg} / \mathrm{kg}$ (X symbol).

Figure 5 depicts the percentage of drug choice and choice trials completed during control sessions and for 8 sessions after the injection of different doses of MCAM. Under control conditions, the average percentage of drug choice for the entire session was between $50 \%$ and $60 \%$ (Fig. $5 \mathrm{a}$, data points above C), and all choice trials were completed each session (Fig. 5b). For the percentage of drug choice, there was a significant main effect of dose of MCAM $[F(2,79)=23.22, P<0.001]$, a significant main effect of session $[F(8,79)=14.23, P<0.001]$, but no significant dose-by-session interaction $(P=0.37)$ (Fig. 5a). There was a significant main effect of dose of MCAM on the number of choice trials completed $[F(2,79)=4.11$, $P=0.02]$, but no main effect of session $(P=0.74)$ and no doseby-session interaction ( $P=0.83$ ) (Fig. $5 b)$. 

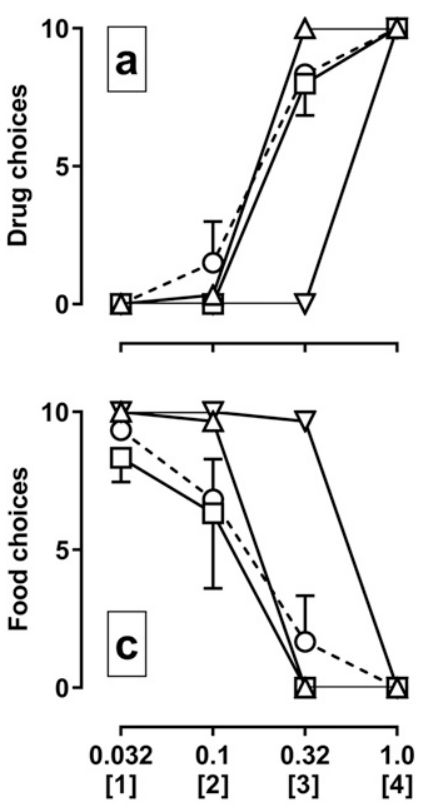
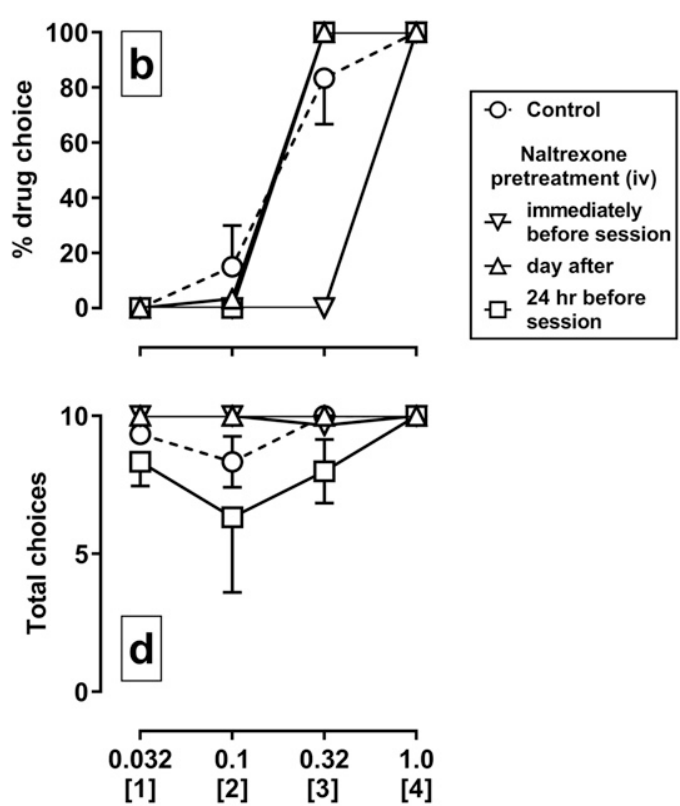

Fig. 3. Effects of $0.032 \mathrm{mg} / \mathrm{kg}$ naltrexone administered intravenously on choice between food and remifentanil in rhesus monkeys $(n=3)$. Choices of remifentanil (a), choices of food (c), the percentage choice of remifentanil (b), and total number choice trials completed (d) are plotted as a function of the unit dose of remifentanil (in micrograms per kilogram per infusion). The dose of remifentanil increased across blocks of the session. Symbols indicate the mean ( \pm 1 S.E.M.) for the group. Circles indicate control data for dose-effect curves for remifentanil alone. Inverted triangles indicate data from a session in which naltrexone was administered immediately prior to the session, and upright triangles indicate data from the next session. Squares indicate data from a choice session in which naltrexone was administered 24 hours earlier, prior to a saline-only choice session (i.e., without an intervening remifentanil choice session).

\section{Remifentanil ( $\mu \mathrm{g} / \mathrm{kg} /$ infusion) [Block]}

Food-Maintained Responding and Physiologic Effects. Monkeys responded at an average rate of 1.5 responses/second and obtained the maximum number (50) of pellets during baseline sessions (Fig. 6, a and b, data points above B). MCAM administered 1 hour prior to the session did not significantly impact the rate of responding or the number of pellets earned on the day of treatment (data points above $\mathrm{T}$ ) or for the four sessions that followed $[0.32 \mathrm{mg} / \mathrm{kg}$ : rate $(P=0.09)$, pellets $(P=0.45) ; 3.2 \mathrm{mg} / \mathrm{kg}$ : rate $(P=0.19)$, pellets $(P$ value not determined)].

During the two 24-hour test periods after vehicle administration, the mean blood pressure ranged from 83.1 to $115.1 \mathrm{mmHg}$ (Fig. 7, a and b), the mean heart rate ranged from 70.4 to 141.0 beats/minute (Fig. 7, $\mathrm{c}$ and d), the mean body temperature ranged from $35.8^{\circ} \mathrm{C}$ to $37.8^{\circ} \mathrm{C}$ (Fig. 7, e and f), and the mean activity counts ranged from 306 to 3189 (Fig. 7 , g and $h$ ). All four measures tended to decrease during the dark cycle of the day, indicated by the shaded regions. For the test with $0.32 \mathrm{mg} / \mathrm{kg}$ MCAM (Fig. 7, left column), there was a significant main effect of hour on blood pressure $[F(23,191)=$ $4.63, P<0.001]$, heart rate $[F(23,191)=6.98, P<0.001]$, body temperature $[F(23,191)=23.65, P<0.001]$, and activity $[F$ $(23,191)=7.99, P<0.001]$, but no main effect of treatment or hour-by-treatment interaction for any of these measures $(P>0.05$ for all dependent variables). For the test with $3.2 \mathrm{mg} / \mathrm{kg}$ MCAM (right column), there was a significant main effect of hour on blood pressure $[F(23,95)=3.08, P<0.001]$, heart rate $[F(23,95)=4.00, P<0.001]$, body temperature $[F(23,95)=27.18, P<0.001]$, and activity $[F(23,95)=2.61$, $P=0.002]$. There was no main effect of treatment of any of these measures $(P>0.05$ for all dependent variables); however, there were significant hour-by-treatment interactions for heart rate $[F(23,95)=2.24, P=0.01]($ Fig. $7 \mathrm{~d})$ and activity $[F(23,95)=2.80, P=0.001]$ (Fig. $7 \mathrm{~h}$ ). A Dunnett's post hoc test indicated that heart rate and activity was significantly lower 20 hours after the administration of
$3.2 \mathrm{mg} / \mathrm{kg}$ compared with heart rate and activity during the same time period of the previous day after the administration of vehicle (Fig. 7, d and h, filled squares); there was no significant difference at any other time point.

\section{Discussion}

Opioid abuse continues to be a significant public health problem. Currently available treatments (methadone, buprenorphine, and naltrexone) are effective in many patients. However, burdensome dosing requirements, limited access to adequate health care, surmountability of opioid receptor blockade (naltrexone), and potentially dangerous drug-drug interactions (methadone and buprenorphine) limit the effectiveness of these medications. Thus, there is a significant need for more and better approaches to treat opioid abuse. This study evaluated the opioid receptor antagonist MCAM for treating opioid abuse by examining its capacity to attenuate opioid self-administration in rhesus monkeys and comparing its effects to those of naltrexone, which is the only antagonist approved for treating opioid abuse.

One group of monkeys responded for intravenous infusions of heroin during daily sessions under a single-lever, fixed-ratio schedule of reinforcement. In that group, heroin maintained high, reliable rates of intake at a unit dose $(0.0032 \mathrm{mg} / \mathrm{kg}$ per infusion) that is at or near the peak of the self-administration dose-effect curve in rhesus monkeys (Gerak et al., 2009; Li et al., 2012; Maguire et al., 2013). Another group of monkeys chose between sucrose pellets and intravenous infusions of the mu-opioid receptor agonist remifentanil. Monkeys chose food over small doses of remifentanil and increasingly chose remifentanil as the unit dose increased across blocks within the session. The potency of remifentanil was comparable to its potency in previous studies (Maguire and France, 2018), and control dose-effect curves were very stable across the study. 


\begin{tabular}{|c|c|c|c|c|c|}
\hline \multicolumn{6}{|c|}{ Days after MCAM injection (iv) } \\
\hline - O. Control & $-\triangle 1$ & $-\nabla 2$ & $\square 4$ & $\diamond 8$ & $* 12$ \\
\hline
\end{tabular}
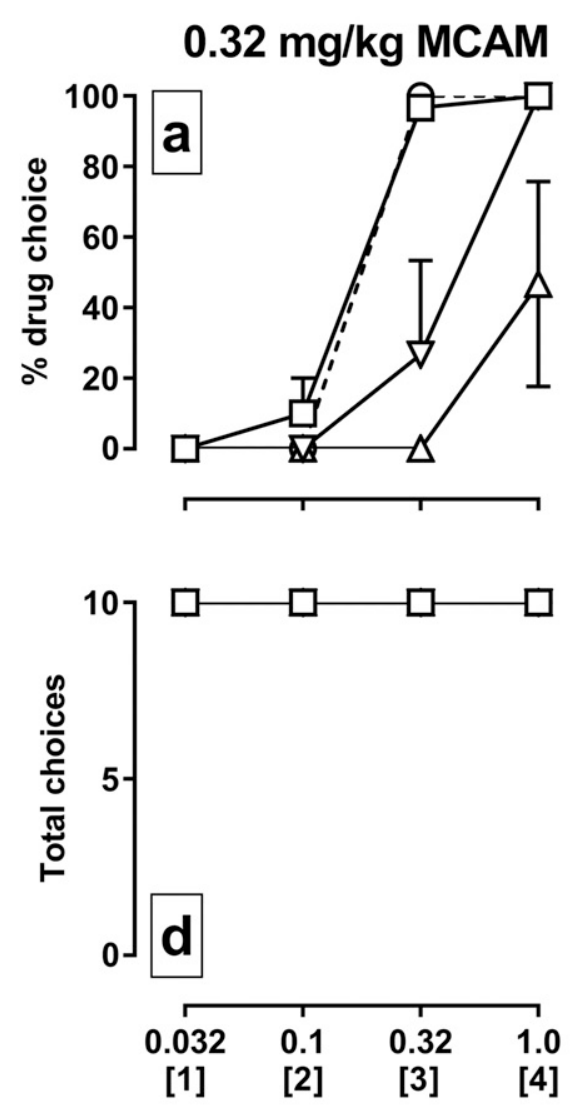

$1.0 \mathrm{mg} / \mathrm{kg} \mathrm{MCAM}$
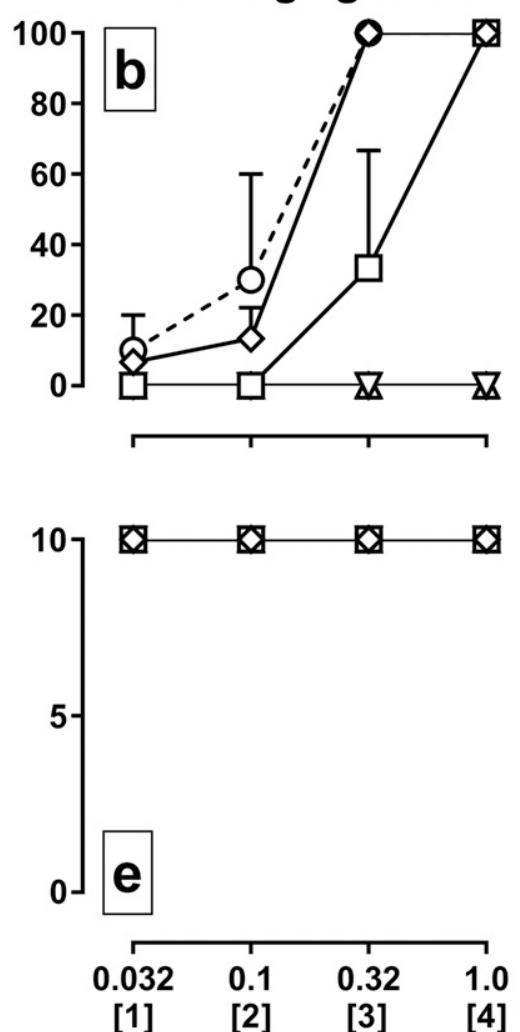

Remifentanil ( $\mu \mathrm{g} / \mathrm{kg} /$ infusion) [Block]
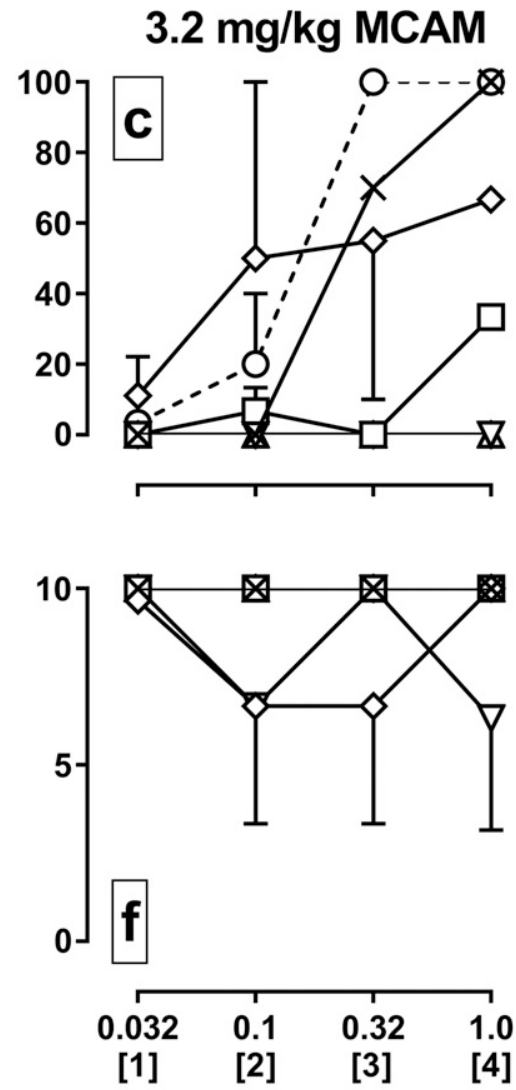

In both groups of monkeys that self-administered an opioid, by reduced heroin intake (Fig. 1) and reduced choice of remifentanil (Fig. 3). In the choice experiment, reduced responding for remifentanil was accompanied by increased choice of food. Like other opioid receptor antagonists, naltrexone promoted a reallocation of behavior away from responding for an opioid and toward responding for the nondrug alternative (food; Negus, 2006). Effective doses of naltrexone in the current study were within the range of those that attenuate many effects of mu-opioid receptor agonists in rhesus monkeys (France et al., 1990; Bowen et al., 2002; Gerak et al., 2003; Gerak and France, 2007; Li et al., 2008; Maguire and France, 2016) including self-administration (Rowlett et al., 1998). Despite the effectiveness of naltrexone, reductions in opioid intake were relatively short lived. Naltrexone produced significant effects on the day of treatment; however, in both experiments responding returned to baseline levels the next day. The short duration of action of naltrexone in rhesus monkeys is consistent with previous studies showing that the potency of naltrexone begins to decrease as soon as 2 hours after injection (Gerak and France, 2007).

MCAM also decreased opioid-maintained responding, and the effects lasted much longer than those of naltrexone. In the heroin self-administration experiment, a single injection of $0.32 \mathrm{mg} / \mathrm{kg}$ MCAM markedly reduced heroin intake on the day of treatment and for several days thereafter, with reductions lasting approximately 10 days on average. In the choice experiment, MCAM reduced responding for remifentanil and increased responding for food. The time to return to baseline responding was positively related to the dose of MCAM. For example, responding recovered completely 4 days after the injection of $0.32 \mathrm{mg} / \mathrm{kg} \mathrm{MCAM}$, whereas the remifentanil doseeffect curve continued to be shifted rightward and downward 4 days after the injection of $3.2 \mathrm{mg} / \mathrm{kg}$ (Figs. 4 and 5). For both experiments, there was variability among subjects in the duration and magnitude of the decreases in opioid intake; however, there was clear evidence in all subjects of a prolonged effect of MCAM exceeding that of naltrexone. Individuals in all experiments were tested with MCAM 

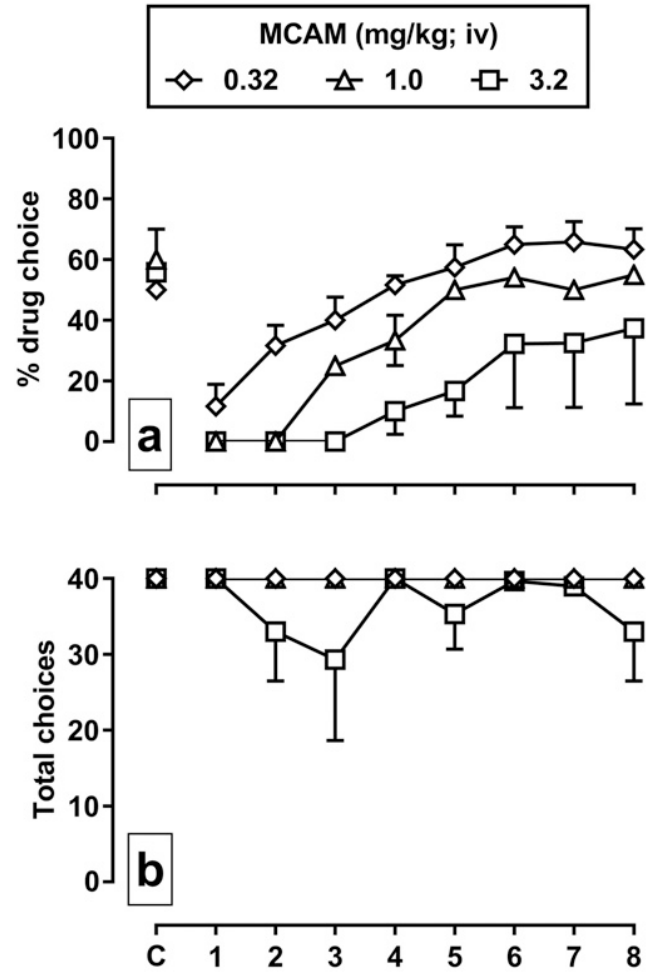

\section{Days after MCAM injection}

Fig. 5. Summary data depicting the effects of MCAM administered intravenously on the percentage choice of remifentanil (panel a) and total choice trials completed (panel b) for each session after the administration of 0.32 (diamonds), 1.0 (triangles), and 3.2 (squares) $\mathrm{mg} / \mathrm{kg} \operatorname{MCAM}(n=3)$. Data points indicate the mean ( \pm 1 S.E.M.) for the group.

multiple times. In the heroin self-administration experiment, sensitivity to naltrexone was confirmed before a subsequent test with MCAM, increasing confidence that the sensitivity of mu-opioid receptors had recovered.

In a previous study (Zernig et al., 1997), clocinnamox, a congener of MCAM and a pseudoirreversible antagonist at opioid receptors, significantly attenuated the selfadministration of the mu-opioid receptor agonists alfentanil and nalbuphine in rhesus monkeys, resulting in a flattening of the self-administration dose-effect curve that in some cases lasted for several days. Although the antagonist effects of clocinnamox and MCAM are long lasting, MCAM is more potent and has greater selectivity for mu- over delta- and kappa-opioid receptors (Broadbear et al., 2000); thus, in a treatment setting it would be expected to have fewer complications than clocinnamox with regard to actions at other opioid receptors.

Collectively, these data provide evidence that MCAM produces significant and prolonged suppression of opioid self-administration in nonhuman primates and suggests that MCAM is superior to naltrexone in its duration of action. Given that adverse outcomes associated with the abuse of many drugs, including opioids, often reflect disproportionate allocation of behavior to drug seeking and taking (Lamb and Ginsburg, 2018), results from the choice experiment are particularly encouraging as far as a single injection of MCAM shifted responding toward the nondrug alternative (food) for several days.
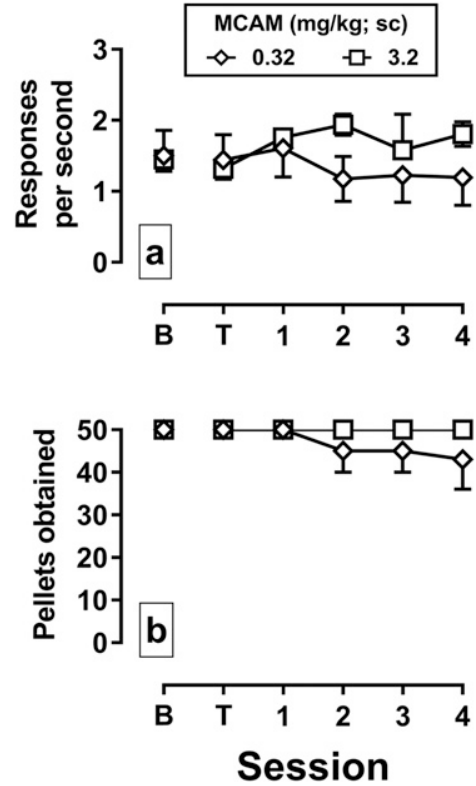

Fig. 6. Effects of MCAM administered subcutaneously on response rate (panel a) and the number of pellets obtained (panel b) in monkeys responding under a fixed-ratio schedule of food delivery. Sessions were divided into five blocks that started every 30 minutes; data are collapsed across all blocks of the session. The mean $( \pm 1$ S.E.M.) response rate and pellets earned for the group are plotted across consecutive sessions. Data points above B are from the session preceding the administration of an MCAM. Data points above $\mathrm{T}$ indicate data from the session beginning 60 minutes after MCAM administration. The abscissae show the time in days since the injection of MCAM. Diamonds indicate data from the test with $0.32 \mathrm{mg} / \mathrm{kg} \mathrm{MCAM}(n=4)$, and squares indicate data from the test with $3.2 \mathrm{~m} / \mathrm{kg}$ MCAM $(n=2)$.

The therapeutic utility of candidate medications for treating drug abuse depends upon whether the medication selectively reduces behavior related to abuse and not all other behavior. Results of the choice experiment provide some evidence of selectivity as far as MCAM decreased responding for remifentanil but not responding for food. However, additional studies were conducted to explore further the selectivity of MCAM. In one experiment, monkeys could self-administer $0.032 \mathrm{mg} / \mathrm{kg}$ per infusion cocaine, a dose near the peak of the cocaine self-administration doseeffect curve in monkeys (Collins et al., 2016). Doses of naltrexone and MCAM that significantly decreased heroin self-administration ( 0.032 and $0.32 \mathrm{mg} / \mathrm{kg}$, respectively) did not alter responding maintained by cocaine on the day of treatment or for several days thereafter. These data are consistent with those of previous studies showing that naltrexone, as well as other opioid receptor antagonists, produce little or no effect on cocaine self-administration in rhesus monkeys (Mello et al., 1990, 1993; Winger et al., 1992; Rowlett et al., 1998). This selectivity has also been demonstrated using the irreversible mu-opioid receptor antagonist $\beta$-funaltrexamine in rats self-administering heroin or cocaine (Martin et al., 1998). Similarly, naltrexone has been shown to block subjective effects (i.e., ratings on a visual analog scale of "How high are you?") of the mu-opioid receptor agonist hydromorphone but not of cocaine in humans (Walsh et al., 1996). MCAM had no effect on responding for food in a third group of monkeys, up to a dose of $3.2 \mathrm{mg} / \mathrm{kg}, 10$-fold larger than the dose that decreased opioid-maintained responding. Moreover, MCAM failed to markedly alter heart 
$\operatorname{MCAM}(\mathrm{mg} / \mathrm{kg} ; \mathrm{sc})$

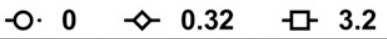
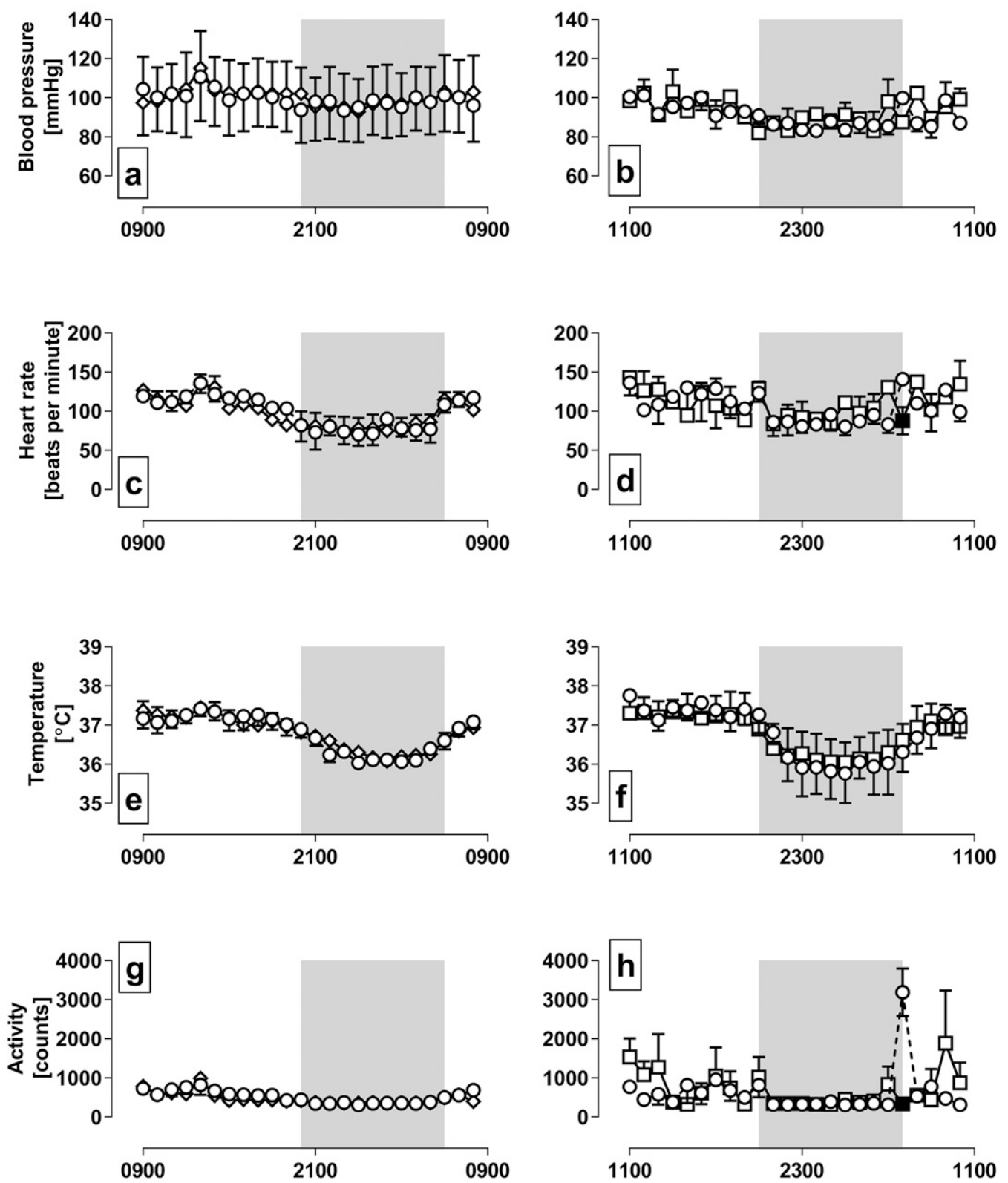

Time of day [h]

Fig. 7. Effects of MCAM administered subcutaneously on physiologic parameters in monkeys instrumented with telemetry devices. Measures of arterial blood pressure (panels a and b), heart rate (panels $\mathrm{c}$ and d), body temperature (panels e and f), and activity (panels g and h) were collected every minute beginning with a vehicle injection on the first day of each 2 -day test and averaged each hour. Circles (all panels) indicate the group mean ( \pm 1 S.E.M.) for each hour for 24 hours after vehicle administration. Diamonds (left column) and squares (right column) indicate data collected after the administration of 0.32 and $3.2 \mathrm{mg} / \mathrm{kg}$ MCAM, respectively. For the test with $0.32 \mathrm{mg} / \mathrm{kg}$ MCAM, injections were given at 9:00 AM, and for the test with $3.2 \mathrm{mg} / \mathrm{kg}$ MCAM injections were given at 11:00 AM. In both cases, injections were given 1 hour prior to the start of the food-maintained operant behavior session. The shaded region indicates the time when the lights were off in the colony room. Filled symbols indicate data obtained after MCAM administration that were significantly different from the corresponding hour after vehicle administration the previous day according to a Dunnett's post hoc test $(P<0.05)$.

rate, blood pressure, body temperature, or activity. There was a significant interaction between treatment and hour for heart rate and activity after the administration of $3.2 \mathrm{mg} / \mathrm{kg}$ MCAM, but a post hoc analysis showed that the difference occurred at only one time point, 20 hours after MCAM administration. This apparent effect of MCAM is the result of an unusual increase in heart rate and activity during the control session coincident with the lights in the 
colony room turning on (compare Figures $7 \mathrm{~d}$ and $7 \mathrm{~h}$ with $7 \mathrm{c}$ and $7 \mathrm{~g}$, respectively). The failure of naltrexone and MCAM to alter responding for cocaine and for food or other physiologic measures, along with the potency of naltrexone, is consistent with the effects of naltrexone and MCAM being mediated by antagonism at mu-opioid receptors rather than "off-target" effects and, together with data from the choice experiment, rules out generalized response rate suppression.

Conclusions. MCAM, an analog of buprenorphine with no efficacy at mu-opioid receptors, dissociates very slowly from the receptor, which results in effects comparable to those of an irreversible antagonist (Broadbear et al., 2000). Because of the very slow dissociation, MCAM has a long duration of antagonist action owing to significant depletion of the pool of functional mu-opioid receptors. Presumably, the duration of effect is directly related to the number of receptors bound by MCAM and the rate of turnover of mu-opioid receptors (Zernig et al., 1994). Such a long duration of antagonist action might be preferable for treating opioid abuse in some patients, especially when access to adequate health care is limited. Pseudoirreversible binding of MCAM to mu-opioid receptors suggests that antagonist effects would not be surmounted by taking larger doses of an opioid agonist. Moreover, MCAM would significantly increase compliance with treatment in so far as the binding of MCAM to opioid receptors cannot easily be reversed, for example, by removing an implant. Because MCAM has no efficacy at mu receptors (Broadbear et al., 2000), there is no risk for the development of physical dependence, and adverse pharmacodynamic interactions with other nonopioid drugs such as alcohol and benzodiazepines are not likely to occur. Thus, treatment with MCAM might be preferred for individuals that coabuse opioids with alcohol or benzodiazepines. MCAM also reverses and prevents heroininduced respiratory depression in monkeys at the same doses and for comparable periods, supporting the use of MCAM for treatment of opioid overdose (Gerak et al., in press). Because MCAM is an antagonist, it might also be expected to precipitate withdrawal in opioid-dependent individuals, as do naloxone and naltrexone, the only opioid antagonists currently approved for treating opioid overdose and abuse, respectively. Thus, like naltrexone, MCAM treatment might require a period of opioid detoxification before treatment induction.

MCAM decreased responding maintained by the opioid receptor agonists heroin and remifentanil but did not significantly decrease responding maintained by cocaine or food. The effects of MCAM lasted much longer than those of naltrexone, with a single injection of MCAM reducing opioid intake for several days or weeks. Formulations could be developed to deliver small doses of MCAM over a long period of time, which would provide continuous blockade of mu receptors. Doses of MCAM that significantly reduced opioid intake did not alter physiologic measures such as blood pressure, heart rate, body temperature, and activity, indicating a favorable safety profile of MCAM with regard to these physiologic parameters. Taken together, these data demonstrate that MCAM can safely and effectively attenuate opioid self-administration for prolonged periods and suggest that this novel drug could be superior to currently available treatments for opioid abuse by improving effectiveness and enhancing compliance in patients.

\section{Acknowledgments}

We thank Jade Juarez, Krissian Martinez, Anastassia Nelson, Emily Spoliarch, and Samuel Womack for excellent technical assistance.

\section{Authorship Contributions}

Participated in research design: Maguire, Gerak, Woods, France. Conducted experiments: Maguire.

Contributed new reagents or analytic tools: Husbands, Disney. Performed data analysis: Maguire.

Wrote or contributed to the writing of the manuscript: Maguire, Gerak, Woods, Husbands, Disney, France.

\section{References}

Becker WC, Fiellin DA, Merrill JO, Schulman B, Finkelstein R, Olsen Y, and Busch SH (2008) Opioid use disorder in the United States: insurance status and treatment access. Drug Alcohol Depend 94:207-213.

Birnbaum HG, White AG, Schiller M, Waldman T, Cleveland JM, and Roland CL (2011) Societal costs of prescription opioid abuse, dependence, and misuse in the United States. Pain Med 12:657-667.

Bowen CA, Fischer BD, Mello NK, and Negus SS (2002) Antagonism of the antinociceptive and discriminative stimulus effects of heroin and morphine by 3-methoxynaltrexone and naltrexone in rhesus monkeys. J Pharmacol Exp Ther 302:264-273.

Broadbear JH, Sumpter TL, Burke TF, Husbands SM, Lewis JW, Woods JH, and Traynor JR (2000) Methocinnamox is a potent, long-lasting, and selective antagonist of morphine-mediated antinociception in the mouse: comparison with clocinnamox, $\beta$-funaltrexamine, and $\beta$-chlornaltrexamine. J Pharmacol Exp Ther 294:933-940.

Collins GT, Gerak LR, Javors MA, and France CP (2016) Lorcaserin reduces the discriminative stimulus and reinforcing effects of cocaine in rhesus monkeys. $J$ Pharmacol Exp Ther 356:85-95.

Gerak LR and France CP (2007) Time-dependent decreases in apparent pA2 values for naltrexone studied in combination with morphine in rhesus monkeys. Psychopharmacology (Berl) 193:315-321.

Gerak LR, Galici R, and France CP (2009) Self administration of heroin and cocaine in morphine-dependent and morphine-withdrawn rhesus monkeys. Psychopharmacology (Berl) 204:403-411.

Gerak LR, Gauthier CR, and France CR (2003) Discriminative stimulus and antinociceptive effects of dihydroetorphine in rhesus monkeys. Psychopharmacology (Berl) 166:351-359

Gerak LR, Maguire DR, Woods JH, Husbands SM, Disney A, and France CP (in press) Reversal and prevention of the respiratory-depressant effects of heroin by the novel $\mu$ opioid receptor antagonist methocinnamox in rhesus monkeys. $J$ Pharmacol Exp Ther Published online ahead of print. https://doi.org/10.1124/ jpet.118.253286

France CP, de Costa BR, Jacobson AE, Rice KC, and Woods JH (1990) Apparent affinity of opioid antagonists in morphine-treated rhesus monkeys discriminating between saline and naltrexone. J Pharmacol Exp Ther 252:600-604.

Hall AJ, Logan JE, Toblin RL, Kaplan JA, Kraner JC, Bixler D, Crosby AE, and Paulozzi LJ (2008) Patterns of abuse among unintentional pharmaceutica overdose fatalities. JAMA 300:2613-2620.

Jones CM and McAninch JK (2015) Emergency department visits and overdose deaths from combined use of opioids and benzodiazepines. Am J Prev Med 49: 493-501.

Jones JD, Mogali S, and Comer SD (2012) Polydrug abuse: a review of opioid and benzodiazepine combination use. Drug Alcohol Depend 125:8-18.

Jones CM, Paulozzi LJ, and Mack KA; Centers for Disease Control and Prevention (CDC) (2014) Alcohol involvement in opioid pain reliever and benzodiazepine drug abuse-related emergency department visits and drug-related deaths - United States, 2010. MMWR Morb Mortal Wkly Rep 63:881-885.

Lamb RJ and Ginsburg BD (2018) Addiction as a BAD, a Behavioral Allocation Disorder. Pharmacol Biochem Behav 164:62-70.

Lee JD, Nunes EV Jr., Novo P, Bachrach K, Bailey GL, Bhatt S, Farkas S, Fishman M, Gauthier P, Hodgkins CC, et al. (2018) Comparative effectiveness of extendedrelease naltrexone versus buprenorphine-naloxone for opioid relapse prevention (X:BOT): a multicentre, open-label, randomised controlled trial. Lancet 391: 309-318.

Li JX, Koek W, and France CP (2012) Interactions between $\Delta(9)$-tetrahydrocannabinol and heroin: self-administration in rhesus monkeys. Behav Pharmacol 23: $754-761$.

Li JX, McMahon LR, and France CP (2008) Comparison of naltrexone, $6 \alpha$-naltrexol, and $6 \beta$-naltrexol in morphine-dependent and in nondependent rhesus monkeys. Psychopharmacology (Berl) 195:479-486.

Maguire DR and France CP (2016) Interactions between cannabinoid receptor agonists and mu opioid receptor agonists in rhesus monkeys discriminating fentanyl. Eur J Pharmacol 784:199-206.

Maguire DR and France CP (2018) Reinforcing effects of opioid/cannabinoid mixtures in rhesus monkeys responding under a food/drug choice procedure. Psychopharmacology (Berl) 235:2357-2365.

Maguire DR, Yang W, and France CP (2013) Interactions between $\mu$-opioid receptor agonists and cannabinoid receptor agonists in rhesus monkeys: antinociception, drug discrimination, and drug self-administration [published correction appears in $J$ Pharmacol Exp Ther (2014) 348:490-491]. J Pharmacol Exp Ther 345:354-362. Martin TJ, DeMontis MG, Kim SA, Sizemore GM, Dworkin SI, and Smith JE (1998) Effects of beta-funaltrexamine on dose-effect curves for heroin self-administration 
in rats: comparison with alteration of [3H]DAMGO binding to rat brain sections. Drug Alcohol Depend 52:135-147.

Martin TJ, Dworkin SI, and Smith JE (1995) Alkylation of mu opioid receptors by beta-funaltrexamine in vivo: comparison of the effects on in situ binding and heroin self-administration in rats. J Pharmacol Exp Ther 272:1135-1140.

Mello NK, Lukas SE, Mendelson JH, and Drieze J (1993) Naltrexone-buprenorphine interactions: effects on cocaine self-administration. Neuropsychopharmacology 9:211-224.

Mello NK, Mendelson JH, Bree MP, and Lukas SE (1990) Buprenorphine and naltrexone effects on cocaine self-administration by rhesus monkeys. J Pharmacol Exp Ther 254:926-939.

National Research Council (2011) Guide for the Care and Use of Laboratory Animals, 8th ed, National Academies Press, Washington, DC

Negus SS (2006) Choice between heroin and food in nondependent and heroindependent rhesus monkeys: effects of naloxone, buprenorphine, and methadone. $J$ Pharmacol Exp Ther 317:711-723.

Negus SS, Henriksen SJ, Mattox A, Pasternak GW, Portoghese PS, Takemori AE, Weinger MB, and Koob GF (1993) Effect of antagonists selective for mu, delta and kappa opioid receptors on the reinforcing effects of heroin in rats. J Pharmacol Exp Ther 265:1245-1252.

Peckham EM, Barkley LM, Divin MF, Cicero TJ, and Traynor JR (2005) Comparison of the antinociceptive effect of acute morphine in female and male Sprague-Dawley rats using the long-lasting mu-antagonist methocinnamox. Brain Res 1058:137-147.

Portoghese PS, Larson DL, Sayre LM, Fries DS, and Takemori AE (1980) A novel opioid receptor site directed alkylating agent with irreversible narcotic antagonistic and reversible agonistic activities. J Med Chem 23:233-234.

Rowlett JK, Wilcox KM, and Woolverton WL (1998) Self-administration of cocaineheroin combinations by rhesus monkeys: antagonism by naltrexone. J Pharmacol Exp Ther 286:61-69.
Saloner B and Karthikeyan S (2015) Changes in substance abuse treatment use among individuals with opioid use disorders in the United States, 2004-2013. JAMA 314:1515-1517.

Schuckit MA (2016) Treatment of opioid-use disorders. N Engl J Med 375: 1596-1597.

Stotts AL, Dodrill CL, and Kosten TR (2009) Opioid dependence treatment: options in pharmacotherapy. Expert Opin Pharmacother 10:1727-1740.

Volkow ND and Collins FS (2017) The role of science in addressing the opioid crisis. N Engl J Med 377:391-394.

Walsh SL, Sullivan JT, Preston KL, Garner JE, and Bigelow GE (1996) Effects of naltrexone on response to intravenous cocaine, hydromorphone and their combination in humans. J Pharmacol Exp Ther 279:524-538.

Winger G, Skjoldager P, and Woods JH (1992) Effects of buprenorphine and other opioid agonists and antagonists on alfentanil- and cocaine-reinforced responding in rhesus monkeys. J Pharmacol Exp Ther 261:311-317.

Zernig G, Butelman ER, Lewis JW, Walker EA, and Woods JH (1994) In vivo determination of mu opioid receptor turnover in rhesus monkeys after irreversible blockade with clocinnamox. J Pharmacol Exp Ther 269:57-65.

Zernig G, Lewis JW, and Woods JH (1997) Clocinnamox inhibits the intravenous self-administration of opioid agonists in rhesus monkeys: comparison with effects on opioid agonist-mediated antinociception. Psychopharmacology (Berl) 129:233-242.

Address correspondence to: Dr. Charles P. France, University of Texas Health Science Center, 7703 Floyd Curl Drive (Mail Code 7764), San Antonio, TX 78229-3900. E-mail: france@uthscsa.edu 